\title{
doispontos:
}

\section{É possível haver arte sem fim?}

\author{
Gerson Luís Trombetta \\ Doutor em Filosofia (Pontifícia Universidade Católica do Rio Grande do Sul, 2006), pós-doutor em Filosofia \\ (Universidade Federal de Minas Gerais, 2015), professor dos cursos de graduação em Filosofia e Música e do \\ Programa de Pós-Graduação em História da Universidade de Passo Fundo. \\ gersont@upf.br
}

Resumo: O artigo analisa a finalidade interna da arte, ou seja, como ela se estrutura, que tipo de relação há entre suas partes e sua origem comum com a forma geral do ajuizamento estético. $\mathrm{O}$ argumento principal, seguindo as teses expostas na Crítica da Faculdade do Juízo de Kant, é que as características do juízo sobre o belo encontram na arte um "caso de aplicação" compatível uma vez que as estruturas formais de ambos coincidem. Na produção da arte, quem realiza tal coincidência, na peculiar definição de Kant, é o gênio.

Palavras-Chave: Arte; finalidade; Kant; gênio; juízo estético; beleza.

\section{Is it possible an aimless art?}

\begin{abstract}
This paper examines the internal purposiveness of art which is how art is structured, what kind of relationship there is between its internal parts, as well as its common origin with the general form of aesthetic judgment. The main argument, according to the theses found in Kant's "Critique of Judgment" is that the characteristics of the judgment of beauty find in art a compatible "application case" since their formal structures coincide. In the production of art, the one who makes such a coincidence is the genius, according to Kant's peculiar definition.
\end{abstract}

Key-words: Art; purposiveness; Kant; genius; aesthetic judgment; beauty.

A questão proposta no título é, ao mesmo tempo, simples e complexa. Simples, pois podemos responde-la de modo simples. A resposta seria um óbvio "não". Se a arte é um fenômeno ou um conjunto de objetos que passou a existir, tendo um princípio, então, terá um fim. Como todo evento histórico, a arte teve um início no tempo e, portanto, fatalmente, cessará. Não há como compatibilizar historicidade e eternidade. Entretanto, a noção de "fim" não se restringe a "encerramento". Lalande (1993, p. 411) sugere, no mínimo, seis sentidos diferentes para a palavra "fim" quando a examinamos de acordo com sua origem latina (Finis). "Fim" pode assumir as seguintes variações semânticas: a) a cessação de um fenômeno no tempo, o ponto onde se para, o oposto do começo; b) a perfeição daquilo que se pretendia realizar; c) a própria coisa que se pretende realizar; d) a ideia do objetivo; a intenção; e) o sentido para o qual uma tendência se dirige; f) o destino ou a destinação de um ser.

Além dos sentidos apontados acima, há ainda um outro, que é particularmente inspirador para a reflexão que apresentaremos na sequência. O próprio Lalande (1993, p.411) chama a atenção que no vocábulo latino Finis, também está o sentido de limite, de fronteira, de terminação. Isso remete ao deus romano Terminus, que era personificado num poste ou busto colocado entre propriedades, demarcando os terrenos. Fim então, pode significar uma linha de limite, um marcador a partir do qual a fronteira se define. É exatamente com essa conotação que a pergunta do título foge da obviedade e ganha a complexidade que 
pretendemos trabalhar aqui. Perguntar se é possível haver arte sem fim não é perguntar imediatamente sobre o momento historicamente localizado em que a arte vai sair de cena; é, sim, perguntar sobre o que constitui propriamente a fronteira entre a arte e os demais objetos.

Uma das consequências da alteração de rota da pergunta é empurrar para o centro do debate o tema das finalidades internas da arte, como ela se estrutura, que tipo de relação se estabelecem entre as partes e que tipo de força a gerou. Por outro lado, discutir as finalidades externas da arte, como o seu valor, sua utilidade e seus objetivos, passa para um segundo plano. É claro que a arte, em sua história, assumiu diversos papéis "externos, servindo desde espaço para brincadeiras (jogos), comunicação de ideias e até para o desenvolvimento de habilidades motoras e atividades de concentração. Uma obra de arte, do mesmo modo que uma teoria científica, também permitiria construir associações, distinções e categorizações, contribuindo para a organização da nossa experiência com as coisas, conosco mesmos e com os outros (GOODMAN, 1968). Além disso, a arte também possui o poder de vivificar juízos, produzir sensações e sentimentos, desencadeando prazer ou desprazer.

Para compreender o núcleo dessa diversidade de potências é preciso examinar sua constituição interna, para a forma como as partes se conectam formando a estrutura que chamamos de arte. Na argumentação que segue, operamos com a hipótese de que as teses expostas na Crítica da Faculdade do Juízo (CFJ) oferecem as ferramentas conceituais para deslindar a estrutura interna da composição artística e sua raiz comum com a forma geral do ajuizamento estético. $\mathrm{O}$ argumento principal é que as condições postas ao juízo de gosto sobre o belo encontram na bela arte um "caso de aplicação" compatível uma vez que as estruturas formais de ambos coincidem. Na produção da arte, quem realiza tal coincidência é o gênio, na peculiar definição proposta por Kant.

\section{Das distinções entre "conformidade a fins" (Zweckmässigkeit) e "fim” (Zweck)}

Na Introdução da CFJ, Kant aponta que o prazer deve ser tomado em duas acepções diferentes: um prazer "teórico" (reflexivo), que acompanha os juízos teleológicos, e um prazer genuinamente estético. O prazer, neste segundo caso, desempenha o papel de índice, de sinal da beleza ${ }^{1}$. A primeira manifestação do prazer (teórico-reflexivo), ainda que, de alguma forma, esteja ligada ao entendimento, não pode ser buscada no encontro das intuições sensíveis com os conceitos puros, o qual é simplesmente espontâneo. O prazer, no contexto teórico, apareceria quando a criação de um universal pela faculdade do juízo reflexivo coincidisse com uma possibilidade objetiva de união das leis empíricas:

Por sua vez, a descoberta da possibilidade de união de duas ou várias leis da natureza empírica, sob um princípio que integre ambas, é razão para um prazer digno de nota, muitas vezes até de uma admiração sem fim, ainda que o objeto deste seja bastante familiar. (CFJ, Int. B XL, p. 31).

Poderíamos chamar isso de "prazer do conhecimento". Enquanto na atividade espontânea do entendimento reina um "certo tédio", no processo reflexivo a possibilidade de concordância da unidade imaginada com a unidade realizada objetivamente causa expectativa. Se a concordância acontece, experimentamos um sentimento de prazer; do contrário, a frustração é desprazerosa. Esse prazer é o sinal do progresso no conhecimento da natureza e, ao mesmo tempo, é um sentimento de satisfação conosco mesmos pelo uso bem-sucedido de nossas capacidades cognitivas.

Existe, no entanto, um outro tipo de prazer. Trata-se do prazer propriamente estético. Para Kant, tal prazer deveria ser definido como "aquilo que na representação de um objeto é meramente subjetivo, isto é, aquilo que constitui a sua relação com o sujeito e não com o objeto” (CFJ, Int. B XLII, p. 32). O prazer (ou 
desprazer) que se liga à representação estética não reverte em fonte de conhecimento, ainda que possa ser até efeito de um conhecimento qualquer. O prazer estético exige, por assim dizer, a suspensão da atividade objetivadora e teleológica.

O sentimento de prazer (ou desprazer) estético nada diz do objeto - é pura sensação experimentada pelo sujeito ao representar para si mesmo um objeto. Isso aponta para um deslocamento da argumentação kantiana no que diz respeito à aplicabilidade dos juízos reflexivos. Até a parte $\mathrm{V}$ da Introdução, tais juízos eram demonstrados como relevantes para as tentativas de sistematicidade científica e para o problema específico da teleologia. Agora, no entanto, o princípio transcendental dos juízos reflexivos aparece em unidade com o sentimento do prazer estético. Na impossibilidade de o ajuizamento estético (reflexivo) atingir o conteúdo do objeto, o argumento kantiano toma a via do que tem sido denominado de "formalismo estético".

O que Kant apresenta na "Introdução" parece resolver melhor aquilo que torna juízos teleológicos e estéticos modalidades de juízos reflexivos do que propriamente determinar as suas diferenças e especificidades. Para encontrá-las precisamos avançar na direção do terceiro momento da "Analítica do belo", onde Kant desenha um argumento essencial: a conformidade a fins dos juízos estéticos subsiste sem a representação de fins, mas com a convicção de se tratar de uma relação que aponta para um fim. É preciso verificar isso mais de perto.

Para Cassirer (1993), o aspecto de onde Kant parte na análise da formação individual do real é o conceito de adequação ao fim (conformidade a fins). Diferentemente da noção atual, que se relaciona com a ideia de um fim consciente, uma criação intencional, o uso linguístico da expressão conformidade a fins no contexto kantiano, muito de acordo com o sentido usual do século XVIII, refere-se à coordenação das partes de um todo múltiplo para formar uma unidade. Não se trata de uma justaposição de partes, uma ao lado da outra, mas, sim, de uma relação que "faz com que o todo se converta de um simples conglomerado em um sistema harmônico, em que cada membro tem uma função própria e peculiar e todas essas funções guardam entre si tal harmonia que se unem em uma obra total unitária e em uma significação de conjunto" (CASSIRER, 1993, p. 337). Ao contrário da metafísica tradicional, que via na conformidade a fins um traço ontológico que ordenava e regulava as leis particulares, para o projeto crítico kantiano não se trata de uma forma da realidade, mas da forma dos nossos conceitos em geral.

O fato de nossa capacidade cognitiva precisar pressupor, para sua própria operação, uma conformidade a fins para compreender campos da experiência já está claro. O problema aparece nos juízos estéticos: como pensá-los unidos ao princípio da conformidade a fins se, por princípio, recusam qualquer fim, seja ele objetivo (teórico) ${ }^{3}$ ou subjetivo (agradável)? A resposta kantiana é, no mínimo, intrigante:

Logo, nenhuma outra coisa senão a conformidade a fins subjetiva na representação de um objeto sem qualquer fim (objetivo ou subjetivo), conseqüentemente a simples forma da conformidade a fins na representação, pela qual um objeto é dado, pode, na medida em que somos conscientes dela, constituir a complacência, que julgamos como comunicável universalmente sem conceito, por conseguinte, o fundamento determinante do juízo de gosto. (CFJ, $\$ 11$, B 35, p. 67).

A citação contém elementos decisivos e, por isso, é conveniente dividirmos a continuidade da argumentação em dois momentos: o primeiro (i) deve diferenciar conformidade a fins de fim e o segundo (ii) deve demonstrar que a conformidade a fins, enquanto fundamentadora do juízo estético, é simplesmente formal.

(i) A definição de fim (Zweck) aparece na CFJ na perspectiva da articulação entre causa e efeito. Então, "fim é o objeto de um conceito, na medida em que este for considerado como a causa daquele (o fundamento real de sua possibilidade)" (CFJ, $\$ 10, B 32$, p. 64). É preciso registrar que a abordagem do que seja fim atende a propósitos transcendentais e não pressupõe algo empírico (como é o caso do sentimento de prazer 
imediato). Estamos pensando um fim quando não estamos pensando somente o objeto, mas o próprio objeto (forma e existência) como um efeito (Wirkung). Um fim aparece, em outras palavras, quando a representação do efeito determina o modo como compreendemos a causa.

Já a conformidade a fins (Zweckmässigkeit - forma finalis) é definida como "a causalidade de um conceito com respeito a seu objeto" (CFJ, $\$ 10, B$ 32, p. 64), ou seja, ter um fim significa ao objeto dever ao conceito desse fim não só a forma como a própria existência. Por sua vez, ser conforme a fins significa uma relação bem mais enfraquecida e diz respeito à possibilidade de se pensar um objeto, ação ou estado de ânimo admitindo como fundamento uma causalidade segundo fins, isto é, "uma vontade que a tivesse ordenado desse modo segundo a representação de uma certa regra” (CFJ, $\$ 10$, B 33, p. 65). Mais uma vez, aqui se explicita um recurso bastante comum na CFJ, a analogia. Ser conforme a fins significa comportar-se como se houvesse uma regra sendo seguida. Não se trata de uma regra objetiva, mas de um pressuposto da operação reflexiva. As consequências disso deverão ser exploradas mais adiante.

O vínculo entre finalidade (conformidade a fins) e sentimento do prazer é mais um sinal de um dos polos de sustentação do projeto crítico: a garantia da objetividade na articulação entre sujeito transcendental e sujeito empírico. Ainda que, no contexto estético, não ocorra uma articulação que vá produzir juízos válidos objetivamente, o que acontece é o delineamento que permita pensar os juízos estéticos como universais, ou melhor, subjetivamente universais.

Tanto no âmbito teórico, como no prático ou estético, o esforço kantiano tem início sempre com o procedimento analítico, que visa, por assim dizer, "depurar" os traços da experiência meramente particulares ou empíricos. Resta saber, como pensar relações finalísticas sem, ao mesmo tempo, pensar um fim que as sustente?

A conformidade a fins pode, pois, ser sem fim, na medida em que não pomos as causas desta forma em uma vontade, e contudo somente podemos tornar compreensível a nós a explicação de sua possibilidade enquanto deduzirmos de uma vontade. Ora, não temos sempre a necessidade de descortinar pela razão [einsehen] (segundo a sua possibilidade) aquilo que observamos. Logo, podemos pelo menos observar uma conformidade a fins segundo a forma - mesmo que não lhe ponhamos como fundamento um fim - como matéria do nexus finalis - e notá-las em objetos, embora de nenhum outro modo senão por reflexão. (CFJ, $\$ 10$, B 34, p. 65-66).

(ii) Podemos, a partir dessa citação, levantar a suspeita de que, por trás da complexidade da exposição kantiana se esconde uma intuição relativamente simples: em algumas experiências que fazemos com o mundo (de modo especial com a natureza e com a arte) podemos "sentir" que os objetos são representáveis como se fossem formalizados de acordo com princípios organizativos (regras). Esse "sentir" não é algo que a atividade de "descortinar pela razão"4 pode explicar ou apresentar os mecanismos objetivos de tal ordenamento. É um evento que ocorre num terreno desinteressado, mas que produz no sujeito um estado de prazer. Por esse motivo, beleza é algo sentido como a "forma da conformidade a fins de um objeto, na medida em que ela é percebida nele sem representação de um fim”. (CFJ, $\$ 17$, B 61, p. 82).

A essa altura é preciso apresentar melhor um paradoxo que brota dos raciocínios kantianos. A argumentação delineada na "Analítica" parecia deixar bastante explícito que o exercício do gosto é marcado totalmente pela transposição em juízo de um sentimento de prazer ou desprazer vivenciado pelo sujeito. É preciso levar em conta, porém, o grau de dificuldade em compatibilizar a tese subjetivista da "Analítica" com o que está sendo exposto na "Introdução" sob o conceito de reflexão. Qual seria a alternativa, então? Temos adotado a interpretação de que o ajuizamento de gosto tem um sentido mais profundo, que não se esgota no terreno estético, mas "presta serviço" ao campo moral (liberdade) e cognitivo. Isso implica aceitar que deve haver "algo mais", algo de objetivo, enquanto "valor" que um objeto mesmo deva possuir - e que realize objetivamente 
a conformidade a fins - para sustentar a "raiz comum" que há entre a harmonia das faculdades cognitivas e a organização da própria natureza. Isso poderia ser exposto no seguinte teorema: na acepção de Kant, os juízos de gosto só se realizam na medida em que, num determinado sentido, a beleza fosse uma natureza ou constituição (Beschaffenheit) objetiva do objeto. O sentido determinado não deve aqui ser compreendido como um conceito, padrão ou qualidade empírica, mas como, simplesmente, uma condição formal.

Nas palavras de Kulenkampff (1992, p. 16), um objeto conforme a fins (mas sem fim) pode ser descrito como uma estrutura integrada,

[...] na qual todas as partes ou elementos combinam de tal maneira ou formam um todo de maneira que não se pode omitir nem acrescentar nada sem destruir a totalidade. Tudo combina e se integra como se tivesse sido organizado com vistas a fins; $\mathrm{e}$, não obstante, essa integração não deriva da determinação do fim da coisa ou da determinação da função dos elementos. Pode-se perceber a forma da conformidade a fins, isto é, a beleza, por exemplo, em objetos da natureza, sem que haja a necessidade de introduzir aqui o mais ligeiro conceito de um fim ou de uma função de um órgão.

A beleza de um objeto é a sua forma (Gestalt), ou, simplesmente, a forma da conformidade a fins. Tal estrutura formal não pode ser descrita ou conhecida; é apenas e tão-somente algo que podemos "sentir" num objeto. Por que sentimos isso na presença do objeto permanece, em última análise, um mistério. $\mathrm{O}$ exemplo de Kant é bastante eloqüente:

Flores são belezas naturais livres. Que espécie de coisa uma flor deva ser, dificilmente o saberá alguém além do botânico; e mesmo este, que no caso conhece o órgão de fecundação da planta, se julga a respeito através do gosto, não toma em consideração este fim da natureza. (CFJ, $\mathbb{\$} 16$, B 49, p. 75 ).

Mais uma vez, o exemplo procura garantir uma distância segura entre cognição e gosto. Entretanto, poderíamos argumentar na direção contrária perguntando: se a forma da conformidade a fins é uma qualidade objetiva e se nosso juízo acerca da beleza se refere a esse estado de coisas objetivo, por que tal conceito não poderia servir de critério (objetivo) para distinguir o belo do não-belo? Ou, em outras palavras, por que os juízos estéticos não poderiam ser uma modalidade dos juízos cognitivos? A explicação dos juízos estéticos por essa via é inviável por dois motivos básicos. O primeiro, porque os juízos de gosto são singulares, ou seja, o adjetivo belo só é aplicável com legitimidade ao objeto que está sendo representado naquele momento. Não é possível autorizar, com base nessa experiência singular, que os próximos objetos da mesma classe sejam portadores de beleza. Como indica Kulenkampff(1992, p.17), "é certo que qualidades estéticas como a da beleza são naturezas dos objetos, mas elas não são qualidades essenciais das coisas: elas não estão ligadas ao seu conceito" (grifo do autor). As qualidades estéticas são qualidades formais e não se segue "como" elas serão realizadas em cada caso particular. Cada objeto pode, por assim dizer, realizar a beleza de infinitas maneiras. Podemos dar razão a Kant, portanto, em sua ideia de que não pode haver nenhum princípio objetivo para o gosto, embora a beleza possa ser compreendida também como uma qualidade objetiva. $\mathrm{O}$ segundo motivo pelo qual juízos estéticos não podem ser confundidos com cognitivos é que a instância decisiva para o nosso ajuizamento sobre o belo é a evidência subjetiva do nosso sentimento de prazer ou desprazer. A "constatação" da beleza é uma experiência totalmente dependente do ato da percepção e, como já explicamos anteriormente, da mobilização harmônica das faculdades da imaginação e do entendimento.

Temos chegado a um ponto decisivo agora: a questão da evidência subjetiva do sentimento de prazer (ou desprazer) e sua compatibilidade (coincidência) com certas estruturas formais dos objetos. Já referimos que o particular estado de ânimo (Gemüt) na percepção do belo não é o mesmo por ocasião do conhecimento determinado; entretanto, o jogo livre das faculdades, assim como ocorre no conhecimento determinado, também permite a congruência de operações (Leistungen). Isso significa que o jogo livre das faculdades é um modelo do conhecimento em geral (CFJ, $\$ 9$, B 28, p. 61). O prazer, então, é mais que forma de percepção 
do belo, mas uma consciência de que o livre-jogo das faculdades de conhecimento preenche o modelo e conhecimento em geral. Isso faz da beleza um sinal de algo que nos põe além de uma experiência restrita ao campo estético-subjetivo e nos aproxima dos velhos problemas da dedução transcendental da CRP. A beleza é o sinal que a natureza, através da forma do objeto, se dá, a partir dela mesma, ao conhecimento em geral. Seguimos, nesse particular, a afirmação de Kulenkampff (1992, p.22), de que as coisas se passam como se, no belo, a natureza nos assegurasse da sua cognoscibilidade ou, em outras palavras, "como se o belo da natureza fosse um penhor dado a nós pela própria natureza, um penhor de que como seres necessitados de conhecimento haveremos de poder satisfazer a nossa necessidade de conhecimento também no concreto e no singular".

\section{Gênio, arte e natureza}

E como a arte pode ser posicionada na equação formal descrita acima? Como compatibilizar as exigências de uma experiência com a natureza, cuja conformidade a fins independe da intervenção humana, com um objeto que deve sua origem a uma vontade racional? A existência ou não de uma teoria da arte na CFJ é assunto de constante debate na literatura secundária sobre Kant. Segundo Kuypers (1972), por exemplo, a interpretação tradicional da CFJ baseia-se num mal-entendido originado na recepção imediata da obra - em especial pela leitura de Schiller e, sobretudo, de Hegel. O que essas interpretações buscaram encontrar na terceira crítica, ao mesmo tempo lamentando sua ausência, foi uma filosofia da arte. Essa busca, de certo modo infrutífera, ainda conforme Kuypers, (1972), bloqueou, desde o início, a possibilidade de se considerar a CFJ como um todo acabado. A CFJ seria uma obra que reuniria sob o mesmo título reflexões que interessariam a estetas e filósofos da arte, por um lado, e a físicos e biólogos, por outro, não contendo uma estética no sentido hegeliano de filosofia da arte, da obra de arte e do artista. E não é raro encontrarmos na CFJ usos bem distintos dos termos arte, obra de arte e artista daqueles usados por Hegel nas suas Vorlesungen über die Ästhetik. "Arte", para Kant, significaria tudo aquilo que a mão humana realiza e "artista", quem é capaz de fazer algo. Ainda segundo Kuypers, parece evidente que as belas-artes ocupam importante espaço na primeira parte da CFJ, mas é evidente, também, que não é seu assunto principal. A questão central seria a teleologia, cujos conceitos deveriam resolver o problema do trânsito entre a razão teórica e a razão prática, ou, mais precisamente, a relação entre natureza e liberdade. $O$ exame dessa temática teria como pano de fundo a concepção de natureza como algo que o homem precisa pressupor (princípio subjetivo) como "técnica" (voltada à realização de certos fins). Tal seria o motivo por que, nas "Introduções"s, os juízos reflexivos funcionam como um "guarda-chuva" que abriga tanto a parte estética como a teleológica da crítica.

Não faltam razões para a posição de Kuypers. Apresentamos acima argumentos demonstrando como a CFJ se alimenta do propósito de desenvolver "garantias" para a compatibilização entre homem e natureza (mundo), tanto do ponto de vista cognitivo quanto do moral. Tal leitura dá os contornos de uma obra voltada a um claro primado sistemático, capaz de integrar a experiência estética e o conhecimento da natureza como organismo (teleologia) no interior do projeto crítico-transcendental de filosofia. No entanto, afirmar categoricamente que na CFJ não é possível encontrar uma filosofia da arte (em sentido amplo) parece-nos demasiadamente radical. Além do mais, isso poderia desperdiçar certas noções, carregadas de potenciais explicativos a respeito da condição da arte, que insistem em brotar das páginas da CFJ, principalmente quando Kant reflete sobre o papel do gênio e sobre a relação entre arte e natureza.

As pistas de como podem ser compreendidas as tensões e distensões entre arte e natureza ganham uma formalização importante no título do parágrafo 45 da CFJ: "Arte bela é uma arte enquanto ela ao mesmo tempo parece ser natureza". Tal título indica algumas sutilezas. Em primeiro lugar, poderíamos imaginar que a arte bela poderia ser aprazível ao ajuizamento de gosto apenas enquanto nos remetesse a um modelo original que sempre seria um produto da natureza. Mas isso já foi demonstrado como inviável; não é esse 
o caminho que o "parecer ser" (zu sein scheinen) indica. Outra possibilidade, esta sim bem mais plausível, é que o parágrafo 45 estaria substituindo a imitação pela analogia ${ }^{6}$. O denominador comum da analogia entre arte e natureza é a beleza. Ao introduzir na natureza mecânica e cega o princípio da conformidade a fins, $\mathrm{o}$ homem pode também compará-lo com a arte. Diante da arte bela, “[...] tem-se que tomar consciência de que ele é arte e não natureza. Todavia, a conformidade a fins na forma do mesmo tem que parecer tão livre de toda coerção de regras arbitrárias, como se ele fosse um produto da simples natureza”. (CFJ, $\$ 45$, B 179, p. 152). É como se existisse uma tensão constante entre o duplo movimento da consciência que realiza a experiência estética: a conformidade a fins efetivamente presente na obra de arte (bela) é negada para projetar, no seu lugar, uma conformidade a fins que um belo espetáculo da natureza suscitava (LEBRUN, 1993, p. 538). Essa tensão na experiência com a arte bela, talvez pelos mesmos motivos da nossa relação prazerosa com o belo natural, nos arrebata e gera satisfação: "A natureza era bela se ela ao mesmo tempo parece ser arte; e a arte somente pode ser denominada bela se temos consciência de que ela é arte e de que ela apesar disso nos parece ser natureza" (CFJ, $\$ 45$, B 179, p. 152). A condição é que a arte apareça "[...] sem que transpareça a forma acadêmica, isto é, sem mostrar um vestígio de que a regra tenha estado diante dos olhos do artista e algemado as faculdades de seu ânimo" (CFJ, \$ 45, B 180, p. 152).

Arte bela e natureza podem até ser semelhantes na aparência externa. Um pintor pode, por exemplo, retratar com fidelidade uma paisagem natural ou um músico pode compor a partir do canto dos pássaros, mas não é por causa da perfeição dessa imitação que natureza e arte se aproximam. A semelhança deve ser buscada na dinâmica da produção: exige-se que a arte não reproduza a natureza, mas que produza como ela, de modo originário e espontâneo. O problema, agora, é compreender a natureza interna dessa intenção indeterminada e espontânea que move o ato produtivo da arte bela, ou "como a imaginação do artista pode se subtrair ao constrangimento do entendimento a ponto de que seu trabalho adquira $\mathrm{o}$ aspecto de uma livre criação?” (LEBRUN, 1993, p. 538), ou, ainda, como a poiética pode se transformar em poética? A resolução das questões assinaladas pode ser, ao menos parcialmente, encontrada na noção kantiana de gênio (Genie):

Gênio é o talento (dom natural - Naturgabe) que dá regra à arte. Já que o próprio talento enquanto faculdade produtiva inata do artista pertence à natureza, também se poderia expressar assim: Gênio é a inata disposição de ânimo (ingenium) pela qual a natureza dá regra à arte (CFJ, $\$ 46, \mathrm{~B} 181, \mathrm{p} .153)$.

A tensão entre "necessidade da regra" e "ausência da ideia da regra" no ato poiético seria solucionada pelo gênio (Genie). Gênio e regra relacionam-se, por um lado, de modo negativo: a atividade do gênio é indeterminada, não pode ser traduzida em processos de ensino e aprendizagem e excede a qualquer prescrição; por outro, a mesma relação pode ser vista de maneira positiva: a produção artística é um ato livre, exemplar, que não permite uma apropriação direta e que provoca "gratuitamente" o efeito da beleza. A ação do gênio de "dar a regra" pode ser interpretada, assim, como um "descobrir a regra" no próprio ato de criação. Toda a arte necessita de regras: "[...] não há nenhuma arte bela na qual algo mecânico que pode ser captado e seguido segundo regras, e portanto algo acadêmico, não constitua a condição essencial da arte” (CFJ, $\$ 47$, B 186). Para produzir a arte, algo tem de ser pensado como fim; do contrário, seria mero acaso. Essa afirmação parece conflitar com outra, posta logo antes: a "arte bela não pode ter ideia da regra segundo a qual ela deve realizar o seu produto". (CFJ, $\$ 46$, B 182).

O conflito só se resolve quando se compreende o "dar a regra", não como um ato autárquico do gênio, produto de uma postura do "eu" - no sentido fichteano de consciência absoluta de si. Num sentido quase oposto, é a natureza que, através do gênio, dá regra à arte. $\mathrm{O}$ artista é, por assim dizer, um médium que a natureza utiliza para a realização de seus supostos fins. A natureza que age pelo gênio é qualquer coisa de, ao mesmo tempo, racional e instintiva, algo que é consequente (enquanto ato produtivo), mas que permanece indomável e indizível. 
Além de incluir o momento da recepção como traço fundamental da experiência estética, a $\mathrm{CFJ}$ não se furta de abordar as características do objeto artístico e o modo como este pode ser objeto do ajuizamento reflexivo estético. Diferentemente de outros artefatos, as obras de arte são feitas como conformes a fins sem a representação de um fim (finalidade sem fim), algo que só é possível pelo talento do gênio criador. Esse talento aproximaria o ato da criação da arte com a natureza e não estaria sob o controle total da racionalidade técnica, nem as regras dos seus produtos poderiam se transformar em um receituário. As obras do gênio não são governadas por princípios já estabelecidos, nem podem ser objeto de um juízo determinante porque não constituem casos possíveis de regras a priori. $\mathrm{Na}$ ausência de categorias estanques, tanto de produção quanto de interpretação, cada obra (ou cada texto) é a exposição dessa falta essencial, desse inominável sempre diferido dos critérios de legitimação e comunicação. Com respeito à pergunta que mobilizou o artigo, abre-se, no horizonte da atuação do gênio, a possibilidade de uma resposta positiva, ao se substituir o "fim" pela formal "conformidade a fins", um tipo de ação reduzida da subjetividade que parece antecipar os rumos que a produção artística moderna e contemporânea acabou percorrendo.

\section{NOTAS}

1. Seguimos, aqui, as teses apresentadas por Jens Kulenkampff, apresentadas em Kants Logik des ästhetischen Urteils (1978) e sintetizadas nos artigos "A lógica kantiana do juízo estético e o significado metafísico do belo na natureza" (1992) e "A chave da crítica do gosto" (2001).

2. A denominação de formalismo estético atribuída a esse ponto da estética kantiana não tem aqui nenhum tom depreciativo ou restritivo. Kant, de fato, confia na ideia de que as qualidades estéticas dependem do ordenamento formal de uma unidade percebida. No entanto, preserva um traço muitas vezes despercebido nas estéticas formalistas contemporâneas: conserva uma estreita conexão entre a experiência estética e as estruturas fundamentais do conhecimento, sem, no entanto, reduzi-la ao campo teórico.

3. Um fim objetivo implicaria aceitar a ideia de perfeição ou conjunto de regras determinadas como fundamento dos juízos estéticos. Um objeto seria ajuizado como belo ou não na medida em que se aproximasse do exemplar perfeito ou obedecesse às regras estipuladas. $\mathrm{O}$ juízo estético não se define por esse caminho.

4. "Descortinar pela razão" é a tradução proposta por Valério Rohden para o verbo alemão einsehen, longamente justificada na nota 45 de sua tradução da CFJ.

5. Tanto na primeira como na definitiva.

6. A analogia é a estratégia mesma da faculdade do juízo reflexivo ao operar com o "como se", delineando o que consiste no princípio da conformidade a fins. Uma definição mais precisa de analogia vamos encontrar na nota referente ao parágrafo 90: "A analogia (em sentido qualitativo) é a identidade da relação entre fundamentos e consequêencias (causas e efeitos), na medida em que tem lugar sem que consideremos a diferença específica das coisas, ou daquelas propriedades em si que contém o fundamento de conseqüências semelhantes (isto é, consideradas fora dessa relação)". (CFJ, \$ 90, B449, p. 304). A estratégia analógica é, portanto, um pano de fundo que acompanha todo o desenvolvimento da CFJ (conforme B XXI - BXXII, p. 21).

\section{REFERÊNCIAS}

CASSIRER, E. Kant, vida y doctrina. México: Fondo de Cultura Económica, 1993.

GOODMAN, N. Languages of art: an approach to a theory of symbols. Indianapolis: Bobbs-Merrill, 1968. 
KANT, I. Kritik der Urteilskraft. 12.ed. Frankfurt: Suhrkamp, 1992.

Crítica da faculdade do juízo. Trad. Valério Rohden e Antônio Marques. 2. ed. Rio de Janeiro: Forense Universitária, 1995.

KULENKAMPFF, J. Kants Logik des ästhetischen Urteils. Frankfurt (M): Vitorio Klostermann, 1978.

. A chave da crítica do gosto. Studia kantiana, São Paulo, v. 3, n.1, p. 7-28, nov. 2001.

. A lógica kantiana do juízo estético e o significado metafísico do belo. In: ROHDEN, Valério (Coord.). 200 anos da crítica da faculdade do juizo de Kant. Porto Alegre: Ed. da Universidade, Instituto Goethe, 1992. p. 9-23.

. Materialen zu Kants "Kritik der Urteilskraft". Frankfurt am Main: Suhrkamp, 1974.

KUYPERS, K. Kants Kunsttheorie und die Einheit der Kritik der Urteilskraft. Amsterdan: North-Holland Publishing Company, 1972.

LALANDE, A. Vocabulário técnico e crítico da filosofia. São Paulo: Martins Fontes, 1993.

LEBRUN, G. Kant e o fim da metafísica. São Paulo: Martins Fontes,1993. 